\title{
Dominant, Hidden and Forbidden Sensemaking The Politics of Ideology and Emotions in Diversity Management
}

Mikkelsen, Elisabeth Naima; Wåhlin, Randi

Document Version

Accepted author manuscript

Published in:

Organization

DOI:

$10.1177 / 1350508419830620$

Publication date:

2020

License

Unspecified

Citation for published version (APA):

Mikkelsen, E. N., \& Wåhlin, R. (2020). Dominant, Hidden and Forbidden Sensemaking: The Politics of Ideology and Emotions in Diversity Management. Organization, 27(4), 557-577.

https://doi.org/10.1177/1350508419830620

Link to publication in CBS Research Portal

\section{General rights}

Copyright and moral rights for the publications made accessible in the public portal are retained by the authors and/or other copyright owners and it is a condition of accessing publications that users recognise and abide by the legal requirements associated with these rights.

Take down policy

If you believe that this document breaches copyright please contact us (research.lib@cbs.dk) providing details, and we will remove access to the work immediately and investigate your claim. 


\section{Dominant, Hidden and Forbidden Sensemaking: The Politics of Ideology and Emotions in Diversity Management}

\section{Elisabeth Naima Mikkelsen and Randi Wåhlin}

Journal article (Accepted manuscript*)

\section{Please cite this article as:}

Mikkelsen, E. N., \& Wåhlin, R. (2019). Dominant, Hidden and Forbidden Sensemaking: The Politics of Ideology and Emotions in Diversity Management. Organization. https://doi.org/10.1177/1350508419830620

\section{DOI: https://doi.org/10.1177/1350508419830620}

Copyright (C) The Author(s) २०19. Reprinted by permission of SAGE Publications.

* This version of the article has been accepted for publication and undergone full peer review but has not been through the copyediting, typesetting, pagination and proofreading process, which may lead to differences between this version and the publisher's final version AKA Version of Record.

Uploaded to CBS Research Portal: May २०२० 


\section{Dominant, hidden, and forbidden sensemaking: The politics of ideology and emotions in diversity management}

\section{Introduction}

Weick's theory of organisational sensemaking focuses on how people give meaning to experience and take action on the basis of that meaning in recursive processes by which organising occurs $(1979 ; 1993 \mathrm{a} ; 1995)$. The strong link of sensemaking to organising is particularly prominent throughout Weick's work, in which he initiated a conceptual shift that made us see sensemaking as the roots of organising by which the 'organisation' becomes constituted. An advantage of applying a sensemaking perspective to organisational phenomena is therefore its ability to capture the lived experiences of social organising, adding richness to our understanding of the complex content of human conditions. While there is no single theory, sensemaking is often defined as a social process that takes place between people as they negotiate and mutually construct meaning to comprehend the world and act collectively (Maitlis, 2005; Weick, 1995). This social process of sensemaking should, however, not be assumed to be democratic, in which all voices are equally legitimate and important. Critics have argued that Weick's sensemaking perspective suffers from an inadequate attention to power, often neglecting the political struggles immanent in collective processes of meaning construction and organising (Maitlis \& Christianson, 2014, Mills, Thurlow \& Mills, 2010, Weick et al., 2005). When people are located at different areas and levels in the organisational hierarchy and they draw on different experiences and areas of knowledge, they often develop conflicting interpretations, which may compete for legitimacy. Although Maitlis and Christianson (2014) noted that it has become much more common to see sensemaking analyses that recognise multiple and competing accounts in organisations, calls have been made to advance our understanding of sensemaking and power in organisations (Sandberg \& Tsoukas, 2015).

This article intends to contribute to this literature by examining more closely the complex mechanisms of the political processes of sensemaking. To do so, we present a qualitative case study of how a diverse workforce experiences diversity management practices in a local branch of a global retail change store, renowned for its central values of and mission to diversity and inclusion. Since diversity developed as an autonomous research field in the 1990s, a polarisation has emerged between mainstream approaches to diversity and critical approaches (Tatli, 2011). The mainstream approaches focus on the business case arguments about the positive performance outcomes of diversity, and they see diversity management as the relatively straightforward and uncontroversial 
application of 'tools' and best practice initiatives to unleash potential (Cox \& Blake, 1991; Özbilgin, Tati, Ipek, \& Sameer, 2014). By contrast, critical approaches argue that the diversity management practices and guides recommended by the mainstream diversity literature have not proved to be effective in achieving greater inclusion of disadvantaged groups, mainly because the practice of diversity management is problematic, contested, and throws up many dilemmas (Ghorashi \& Sabelis, 2013; Janssens and Zanoni, 2014; Zanoni, Janssens, Benschop \& Nkomo, 2010; Wrench, 2005).

Recent contributions to the critical diversity literature attempt to explain the rift between mainstream and critical approaches to diversity by demonstrating that while diversity is socially constructed and ever-changing and thereby is nothing in and of itself, it nevertheless remains imagined and idealised as something very specific (Christensen \& Muhr, 2018). This combination of an empty signifier of diversity and the desired ideal of being a diverse organisation creates space for many contradictions and problems in the management of diversity. In the words of Schwabenland and Tomlinson (2015), the practice of diversity management remains a 'phantasmagoria' because diversity practitioners experience it as muddled and messy, filling the empty space with significations that sow doubt, confusion, and anxiety.

Given these spaces for signification, an opportunity arises to apply a sensemaking lens to explore what meaning and value are assigned to specific practices of diversity management. Whereas Schwabenland and Tomlinson (2015) are concerned with the management of diversity from the perspective of managers and diversity practitioners, we focus specifically on how a diverse workforce itself assigns meaning to the practices of diversity management by drawing particular attention to how power and politics influence sensemaking processes. Specifically, we integrate the sensemaking perspective with a poststructuralist feminist conception of power (Mumby \& Putnam, 1992) to investigate the political processes of sensemaking about diversity management practices at a local branch of the global retail chain store of RETAIL (pseudonym). We address two research questions: What ideological resources do the diverse workforce at RETAIL mobilise in their sensemaking and enactment of diversity management practices? What characterises the political processes of sensemaking about diversity management practices through which organising occurs? Thus, our object of inquiry in this article concerns the political processes through which some sensemaking gains legitimacy and becomes dominant while others remain marginalised with respect to diversity management. 
Our contribution in this article is twofold. First, our theoretical contribution to the sensemaking literature is to demonstrate the potential for combining the sensemaking perspective with a poststructuralist feminist conception of power to extend our understanding of the complex political processes of sensemaking and organising. We show that a variety of sensemaking resources shape the terrain within which organisational members interpret and enact practices of diversity management at work. We moreover show that particular dominant sensemaking resources are routinely employed to control the definition of a specific situation, implicating subjects in a particular social ordering of collective organising. Second, our empirical contribution to the critical diversity literature is to show how the sensemaking perspective can contribute to understanding of how diversity plays out in practice. We specifically demonstrate how a diverse workforce itself assigns meaning to diversity management practices, adding to our knowledge about how diversity is experienced very differently in different locations. To develop our argument, we first present Weick's (1995) theoretical framework of organisational sensemaking, emphasising our focus on power and agency in sensemaking. We then introduce the basic ideas of a poststructuralist feminist conception of power. After having accounted for our research approach, we present the key findings of the dominant, hidden, and forbidden sensemaking of diversity. We end the article by discussing its contribution to scholarship on sensemaking and practical implications.

\section{Theoretical Background}

\section{The sensemaking perspective}

Rooted in symbolic interactionism, sensemaking is the process by which people give meaning to experience and take action on the basis of that meaning (Maitlis \& Christianson, 2014). Weick argues that " $[\mathrm{t}]$ he basic idea of sensemaking is that reality is an ongoing accomplishment that emerges from efforts to create order and make retrospective sense of what occurs" (1993: 635). Sensemaking happens when discrepant cues interrupt individuals' ongoing flow of activity and create uncertainty about how to act. Discrepant cues emerge when there are inconsistencies between expectations and reality and they trigger the development of plausible meaning that explain what occurred (Weick, 1995). The development of plausible meaning involves noticing and bracketing cues from the interrupted situation and interpreting these by placing them into salient preexisting frames to enact a more ordered environment (Maitlis \& Sonenshein, 2010). Sensemaking is a social process because the construction of meaning happens through social interactions with others. Sensemaking should therefore be studied, as argued by Gephart (1993), in the intersubjective social 
world of organisational actors by examining their use of language in talk and discourse because it is through these discursive processes that actors produce 'accounts', albeit that the meanings attributed of such accounts may not reflect collective agreement. As argued by Maitlis and Christianson (2014), sensemaking is a central activity that is often thought of as an ordering force because it enables the accomplishment of key organisational processes. Sensemaking therefore lies at the very heart of organising.

A core feature of the sensemaking perspective is that sensemaking is equally concerned with noticing and responding to cues in how we create the world around us (Daft \& Weick, 1984; Weick et al., 2005). As a process theory, sensemaking involves three main interrelated processes of creation (noticing and extracting cues to create an initial sense of the situation), interpretation (developing the initial sense into a more coherent account of what has occurred), and enactment (acting on the more coherent account) occurring in an ongoing cycle that actors engage in when trying to understand what is happening and restore interrupted activities (Weick, 1995). While together, these constitute the process of sensemaking, Sandberg and Tsoukas (2015) criticise the clarity of the relationship between 'sense' and 'action' in this model. They argue that Weick's linear portrayal of the relationship between 'sense' and 'action' as two distinct processes that interact obscures that they are bound together in a hermeneutic circularity in which social action should be seen as constitutive of the sense that is being made and vice versa (Sandberg \& Tsoukas, 2015). A defining feature of the concept of enactment is precisely its ability to capture that 'sense' and 'action' are inextricably interwoven because "people often produce part of the environment they face" (Weick, 1995: 30), thereby creating the raw materials for sensemaking.

Building further on this notion of a circular relationship between 'sense' and 'action', we focus on organisation members' talk about diversity management, specifically their social practices (Gubrium and Holstein, 2009; Hansen, 2006), to explore how particular ways of making sense of diversity management relate to agency within a specific context of ideological meaning. In effect, we particularly explore how certain forms of control may result in a divergent relationship between 'sense' and 'action' in that although we enact the environment we face, we may in fact make sense of it in ways that are contrary to the social order (Garfinkel, 1967) but still conform to it with our actions. The concept of social order refers to a relatively persistent system of linked social structures, social institutions, and everyday social practices, which enforce and maintain 'normal' and appropriate ways of relating and behaving. Focusing explicitly on sensemaking and enactment in relation to the social order of a specific organisational context, however, raises questions about 
what happens when conflicting interpretations about the same event occur and what mechanisms are employed to control the definition of a specific situation and accomplish collective organising.

\section{Sensemaking and power}

Within the sensemaking literature, Weick's framework has regularly been criticised for its inadequate attention to power and the politics of sensemaking (Maitlis \& Christianson, 2014; Mills et al., 2010; Sandberg \& Tsoukas, 2015; Weick et al., 2005). The critique particularly highlights an assumption in the framework that sensemaking essentially represents a unitarist or negotiated order perspective on organising, in that it is often presumed that organisational actors build their understanding of an issue together as they work collaboratively toward a common goal. Much of sensemaking literature has been concerned with consensus over meaning and how coordinated action and collective organising may be restored in situations of ambiguity (e.g., Gioia, Thomas, Clark \& Chittipeddi, 1994; Weick, 1993b). Other contributions acknowledge the contested nature of meaning in which sensemaking processes may be multiple, ambiguous, and sometimes involve opposing interpretations (Brown, 2005; Balogun \& Johnson, 2004; Mikkelsen, 2013; Patriotta, 2003), processes that Brown, Stacey, and Nandhakumar (2008) term 'discrepant sensemaking'. The conceptualisation of power seen in many of those studies, however, often resembles that of formal authority, assuming that in situations of ambiguity, all organisational members or stakeholders, despite different values or interests, will work to establish consensus over meaning to restore social order. Within this line of inquiry, the change literature has moreover shown that it is common that certain individuals, such as leaders, have more influence than others on interpretation and meaning (Maitlis \& Sonenshein, 2010), a dynamic also known as leader 'sensegiving' (Gioia \& Chittipeddi, 1991)

Another way of capturing the dimension of power in sensemaking is, however, to show how certain kinds of sensemaking structure the order of social reality in a particular organisational context, as well as how other kinds of sensemaking resists that ordering. Such a focus would include how power and dominant assumptions privilege some meanings and identities over others. For example, the importance of being a 'diverse organisation' may be privileged in an organisation through language, rules, and so on that emphasise the characteristics of this identity. The construction of this identity maps out tacit and explicit rules for how staff and management should act, think, and feel in relation to diversity management and each other, perhaps being encouraged to draw upon cues from similar organisations or from broader social contexts to reflect and legitimise 
this identity. A sensemaking perspective should therefore take into account the unequal distribution of power within an organisation and particularly more covert systemic forms of influence in terms of organisational rule systems. While the former leads to some individuals having more influence on interpretation and meaning than others, which is closely linked to the idea of sensegiving (Gioia \& Chittipeddi, 1991), the latter mobilises ideological frames to influence organisational activity and determine appropriate and inappropriate social practices. Combining the sensemaking perspective with a systemic power lens that captures systemic forms of influence would show a variety of resources at work in the political processes of sensemaking, of which formal authority is only one.

To move forward, we adopt Hardy's (1996) notion of power, which holds a neutral view on power, as she views power as a force that directs actions and affects outcomes. This notion of power allows us to study power 'to' rather than power 'over' and to pay close attention to the political processes of sensemaking about diversity management by exploring the mechanisms through which some sensemaking becomes legitimate while others remain marginalised. Drawing specifically on Mumby and Putnam (1992) in their feminist analysis of 'bounded rationality', we combine sensemaking with a poststructuralist feminist framework that is used for examining organisational hegemony/patriarchy through the way organisational actors construct their identities through discursive practices of rules, behaviours, and meaning systems. Similar to Hardy's (1996) approach to power, Mumby and Putnam (1992) draw their basic ideas of poststructuralist feminism from Foucault's (1980) argument about how emerging power/knowledge relations are constantly constituted in intersections of the body, discourses, and social practices. In this framework, the human body is identified as the site of power because it becomes the locus where certain discourses and practices are legitimated and normalised as 'truth' and 'knowledge'. Thus, the body becomes the locus of domination because this is where docility is accomplished and where subjectivity is constituted (Calás \& Smircich, 1999), emphasising the local and intimate operations of power rather than exclusively focusing on the authoritative power of organisational figures, for instance.

Such an approach to power additionally emphasises the crucial role of discourse and ideology, which have the capacity to produce and sustain hegemonic power when treated as a 'given', whilst marginalised discourses and ideologies are constituted as 'other'. Ideologies are systems of meaning, that is, preexisting frames, notions, norms, and models by which we are able to identify our relationships to the world and to others, which guide our conduct and allow for its rationalisation and justification (Mumby, 1987; Wetherell, Stiven \& Potter, 1987). Ideologies may 
be thought of as macro-level discourses (Alvesson \& Karreman, 2000) referring to whole systems of belief.

From the stance of poststructuralist feminism, Mumby and Putnam (1992) critically view power as the process of domination through which influence is established by, on one hand, constructing and cultivating certain organisational ideologies so that they become the dominant and 'given' resources to influence organisational sensemaking and activity. On the other hand, influence is gained by managing and controlling the organisation's culture and prescribing the emotional aspects of organisational life through practices and norms and by inculcating certain values and premises for decision making to secure ideological compliance. Lukes (2005), in his work on the different dimensions of power, argues that the power of meaning, that is, the power that is used to shape perceptions, cognition, and preferences so that the status quo is accepted without imagining any alternative, is about securing others' compliance by controlling their thoughts and desires. However, as Heaney (2011) argues, the securing of compliance to domination can really only happen through the controlling of emotions, since emotions play a central role in creating and sustaining commitments to social structures and cultures.

A poststructuralist feminist conception of power therefore specifically includes emotion management and the idea of feeling rules as central concepts in its theorising, as these are apt for capturing the complex processes of domination and securing compliance. Feeling rules prescribe what we expect we ought to feel in a given situation (Hochschild, 1990). They mark off degrees of appropriateness of a feeling by governing how we should feel and for how long; most often, these rules are not found in training manuals but constructed in social interaction. Acts of emotion management are always guided by an ideological aim acting as a covert control over individuals (Putnam \& Mumby, 1993).

Mumby and Putnam (1992) use a poststructuralist feminist approach to expose a malecentred mainstream organisation theory promoting masculine systems as rational and normal. By contrast, we combine the poststructuralist feminist approach with Weick's theory of organisational sensemaking to focus on the mobilisation of ideologies in processes of diversity management. We specifically explore the political dynamics of sensemaking about diversity management by focusing on how certain ideologies and feeling rules gain appeal and how they determine the terrain of action that unfolds.

\section{Diversity in a Danish context}


In the literature, diversity is often presented as a universal concept without sensitivity to how societal discourses on difference have been formed historically and politically in specific contexts (Risberg \& Søderberg, 2008). To contextualise the present study, we therefore need to turn away from the dominant construction of diversity in the United States and the United Kingdom and instead consider the societal discourse of difference in Denmark. The primary concern of diversity management in Denmark is with ethno-cultural differences (Holck \& Muhr, 2017). These macro trends of diversity management are also reflected in the micro situation of RETAIL, where employees mainly perceive diverse categories as relating to ethnic and cultural differences.

Until the 1960s, Denmark was a highly ethnic homogenous country, but globalisation and increased immigration have made it more multicultural. As of today, immigrants account for an estimated $10 \%$ of the total population (Holck \& Muhr, 2017). The historical development of this turn started with the arrival of invited Turkish 'guest workers' in the 1960s. Since the 1980s, Denmark has experienced an influx of immigrants and refugees from the world's hotspots, the latest of which include people fleeing the wars in Iraq, Afghanistan, and Syria. Today, large numbers of mostly Eastern European migrant workers use the free movement within the EU to seek employment in Denmark (Statistics Denmark, 2017).

Like many other countries, Denmark has experienced challenges with integrating its ethnic minorities into the labour market. Despite decades of active labour market policies, ethnic minorities are still more likely to be unemployed, and they are overrepresented in low-skilled and temporary jobs and underrepresented in management positions. Diversity management was introduced in Denmark primarily as a response to the wave of immigration and to help migrants enter the workforce (Boxenbaum, 2006, Holvino \& Kamp, 2009, Risberg \& Søderberg, 2008). The Danish welfare model has integrated the concept of diversity with an inclusive labour market ideology targeting ethnic minorities as a group that needs help to fit into the labour market. However, labour market policies have also been fused with companies' social responsibility of recruiting weak labour market groups into their organisations (Holck, 2015, Holvino \& Kamp, 2009). Translating diversity management into a Danish context thereby draws on ambiguous labour-market logics: promoting corporate social responsibility, highlighting the business case of diversity, while also portraying minorities as a burden to the society (Holck \& Muhr, 2017).

\section{Methods}


We used a qualitative case study methodology to investigate what characterises the political processes of sensemaking about diversity management practices as well as the ideological resources a diverse workforce mobilise in its sensemaking and enactment of these practices. Using interviews, participant observation, and access to internal documentation, we collected data at RETAIL, a local Danish branch of a global retail chain store, renowned for its central position as one of the Nordic market leaders within diversity management. Because of a very conscious and explicit recruitment strategy of inclusion of differences, employees from all over the world work at RETAIL. Besides an ethnically diverse workforce, RETAIL also hire people from different age groups as well as people with physical and mental impairments.

\section{Empirical material}

The study comprises 18 interviews with both staff and management and approximately 80 hours of participant observations conducted by the second author between February and April 2016. Interviews were conducted with staff members, team leaders, and managers from the four RETAIL departments: The Canteen, Customer Service, the Warehouse, and Top Management. We present an overview of the interviewees in Table 1.

\section{Insert Table 1 about here}

To examine diversity management from the perspective of the diverse workforce at RETAIL, we focused on their accounts of experiences with diversity management. Weick (1995) argues how accounts give insight into people's sense of reality and the ideological norms they draw on when constructing reality. An account does not represent experience but is a filtering of it, drawing on selected plots to create coherence. Accounts are therefore 'powerful stand-alone contents for sensemaking' (Weick, 1995: 129). Each interviewee was therefore asked to produce accounts in which they described situations in which they worked as a part of a diverse team, focusing on the particular ways in which practices of diversity management influenced them. The influence could be positive, negative, or both. In addition to the interviews, participant observations were conducted at the departments of the Canteen, Customer Service, and the Warehouse, yielding fifty pages of field notes. During observations, the researcher took the role of what Tracy (2013) characterises as an 'active participant' of the setting by wearing the RETAIL uniform and name tag and contributing to task processing. Being an active participant had certain advantages in the data collection process as it allowed the researcher to observe the employees at RETAIL closely as they went about their daily routines as well as relationally connecting with them. The latter turned out to 
be particularly critical for gaining access to information because at first, the employees were quite reluctant to talk about their negative experiences with diversity management. However, during the time that was spent at the departments, employees slowly began to open up about situations of conflict, grouping, stereotyping, and discrimination experienced at RETAIL.

\section{Analytical process}

All interviews were transcribed and carefully studied for recurring themes. We used thematic data analysis (Braun and Clarke, 2006) because this method is productive in learning about the patterns and themes in large qualitative data sets. Thematic data analysis involves searching across our data set to find repeated patterns of meaning or frames that staff and management use to explain diversity management. To facilitate our interpretation of the data, we coded the transcripts and field notes by assigning inductive codes to segments of data that described a particular theme. Through an iterative and reflective process, we explored the content of different themes and relationships within and between themes.

We undertook the following steps in analysing the data: First, we conducted close, line-byline readings of the interview transcripts and field notes, searching for as many ideas for themes and patterns as possible, all in relation to emic conceptualisations of diversity management. Second, we conducted the preliminary coding of transcripts and field notes by applying codes to dissect the data material into meaningful and manageable accounts. Throughout this step of the coding process, a constant comparative method was used to compare and modify the data to each code. During this phase, we found accounts about diversity management clearly different in terms of whether they represented opportunities or challenges of working in a diverse workforce. Third and finally, we sorted the different codes into a number of well-developed and recurring themes. Different people experienced opportunities and challenges differently, depending on organisational status. We therefore organised themes and subthemes in terms of departmental groups. Three different levels of sensemaking emerged from the analytical process, and they became the centre for our contribution: dominant, hidden, and forbidden sensemaking.

\section{The politics of ideology and emotions in diversity management at RETAIL}

In line with previous diversity studies, diversity management at RETAIL was constructed in multifarious ways, mobilising ideologies of the business case, social justice, social categorisation, and exploitation. We found that sensemaking of diversity management was organised in a 
hierarchical system of dominant, hidden, and forbidden sensemaking, each representing different meanings about what diversity management means to organisational members (see Table 2).

\section{Insert Table 2 about here}

Moreover, rather than applying a priori categories of difference, we identified those categories of difference that were used by employees and managers at RETAIL, as suggested by Tatli and Özbilgin (2012). Emergent categories of diversity at RETAIL focused predominantly on differences in ethnic or cultural background and on differences in age. Thus, our analysis of how employees and managers assign meaning to the practice of managing diversity focuses particularly on the categorical differences of ethnicity/culture and age.

\section{Dominant sensemaking of diversity management}

The most dominant way to portray diversity management at RETAIL was to talk about it as solely enabling positive opportunities for earnings, employees, and society at large. RETAIL was renowned for its diversity values in the Nordic market, and members of top management ascribed only positive meaning to diversity management. At first sight, their positive accounts appeared to cascade down through the organisational hierarchy, being equally deployed by all team leaders and employees at RETAIL. Values specifying the positive effects of having a diverse workforce were pervasive in employee and managers' accounts. Two dominant accounts of diversity management were particularly salient in the data. The first was employees', team leaders', and top managers' portrayal of diversity management as an unproblematic means that positively affected performance at RETAIL because it always ensured the recruitment of the best individuals. The second was employees' and team leaders' experiences of diversity management practices as producing a positive work environment in which they felt proud to work.

Diversity management as an unproblematic means to increase performance. Top management's talk rested on a firm belief that diversity management was an unproblematic means that made it possible to recruit from a larger pool of talent and thereby hire 'the best person' for a job. Explicitly linking the company's recruitment policy to organisational values of diversity, members of top management confidently referred to diversity management as a strategic asset that added value to RETAIL's bottom line. They saw no problem in hiring individuals from different cultures since everyone, once hired by RETAIL, was expected to adopt its values of tolerance and inclusion: 'No conflict emerge from diversity because at RETAIL we choose people that can cope with this kind of 
environment. Those who work here are all tolerant and understanding people' (Mette, Top Management). Thus, diversity was effectively managed by neutralising individual difference so that only individuals with the 'right type' of attitude were hired.

Guided by top management's firm sensegiving about the positive effects of diversity recruitment, employees and team leaders similarly portrayed diversity management as a strategic asset that increased the performance of individual departments. They often appreciated that diverse employees had multiple perspectives on a problem at hand and that such groups were better inclined to scrutinise problems and generate ideas, leading to more optimal solutions. After an intense debate during a morning meeting in the Canteen, foreign-born employee Marina explained:

'Sitting with people who are like me, our ideas become narrow and single minded. When we are different, we get more viewpoints and different angles. Our differences challenge us and we become better at what we do'.

This dominant construction of diversity management as a means that enhanced performance levels at RETAIL clearly deployed the ideology of business for diversity, emphasising that employing a diverse workforce is good for business.

Diversity management makes us into better people. Whereas top management specifically emphasised how diversity management added value to company earnings, employees and team leaders in all departments additionally portrayed diversity management as benefitting the work environment. They explained that when people of different ages and from different cultures worked together, tolerance would increase and employees simply developed into better people. To illustrate this, we include an observation from the Canteen:

In the Canteen, where Abida works cooking spaghetti meals for customers, the atmosphere is very lively. Metallic pots and pans hang from racks over the stoves. Spices are kept on a tall shelf, but Abida cannot reach them. After a quick comment, her Danish coworker Nicolai rushes to her aid. With a big smile on his face, he says, 'You really have to watch out for her and her African cooking style. The customers will die from a chili attack'. Everyone in the Canteen laughs loudly. Abida smiles as she bites back at him with a sharp comment. Later she says, 'That is the thing, it is really fun to 
work here. We are all different but that makes it more fun. We joke about it and we learn from each other's differences, it is exiting to learn how they do things in other countries'.

Employees extracted humour as a cue for what it felt like to work in a diverse workforce, making work more fun and enjoyable. They explained that working with people with whom they would not normally interact helped them better to understand people who were different and to communicate more respectfully with each other. Especially those who perceived themselves as belonging to the majority of native-born Danish employees told stories of beginning work at RETAIL and developing into a more open-minded and tolerant person. Positive experiences of working in diverse teams were often highlighted through the use a family metaphor: 'I know that many in our department work here because they simply love their RETAIL family. It provides them with a sense of security to work here' (Sofia, team leader). These positive accounts were guided by top management's account of the conflict-free environment, emphasising only the benefits of diverse teams.

An important part of becoming a better person was the native- and foreign-born employees' strong identification with the diversity values of RETAIL, which made them feel extremely proud of being part of an organisation that emphasised diversity and inclusion in its workforce. Marina, a foreign-born Canteen worker, for example, said, 'I really believe in the RETAIL values about difference and the culture here, that's why I stay', and native-born employee Vibeke, from Customer Service, said, 'RETAIL has visions. It has its heart in the right place and wants to help. That makes me incredibly proud of working here. I have told everybody that I work here'. Whereas the native-born Danish employees saw themselves as part of an organisation that gave minorities a chance, the foreign-born employees saw themselves as the minorities who received a chance and were very grateful for the job stability that RETAIL provided for them. The feelings of pride and gratitude evoked a sense of protective loyalty visible in employees' strong identification with RETAIL's diversity values. The construction of diversity management as implementing a set of values for how actors should interact and understand each other deployed the ideology of social justice, emphasising that diversity management is valuable because it is good for people.

The two dominant accounts of diversity management were legitimate ways of interpreting diversity management at RETAIL, emphasising only its positive dynamics. Articulated by top 
management to guide and shape employee sensemaking strategically toward noticing only the positive dynamics of diversity management, the dominant accounts were told and retold by employees and team leaders. Drawing explicitly on the positive ideologies of diversity management and its advantages for business and people, processes of domination shaped the normative climate of collective sensemaking at RETAIL toward unity and cohesiveness in what employees and team leaders could say aloud about working in a diverse organisation and how they would act. Their strong identification with the RETAIL diversity values additionally demonstrates that employees and team leaders were subjected to a relation of belief in the legitimacy of the positive dynamics of diversity management. This relation of belief was constituted and maintained by the positive emotions of pride, joy, love, gratitude, and confidence that employees, team leaders, and top managers felt and expressed about the diverse working environment at RETAIL. Whereas emotions act as meaning-centred frames for experience (Mumby \& Putnam, 1992), positive emotions had become the means for individuals at RETAIL to interpret and adapt to the diverse organisational culture and its social relationships. For many employees and team leaders, emotions were embedded in accounts that positively transmitted diversity values and their ideological framing.

In essence, these positive emotions forged a social bond between top managers at RETAIL and employees and team leaders to sustain their commitments to the social structures at RETAIL. A clear example of this is the use of the emotive metaphor of the RETAIL family to garner legitimacy to the positive dynamics of diversity management. Thus, infused by positive emotions and a strong identification with the diversity values at RETAIL, local sensemaking about diversity management was shaped by the two dominant positive ideologies about diversity management. These ideologies reciprocally guided what organisational actors noticed, thought, and felt about diversity management, setting standards for employees' terrain of action. The continuous articulation of these dominant accounts by both top management, team leaders, and employees, through the telling and retelling of authoritative and positive stories of how exceptionally well diversity management worked at RETAIL, exercised symbolic power by reinforcing the legitimacy of diversity management as something that worked for everybody's benefit.

\section{Hidden sensemaking of diversity management}

While the dominant sensemaking of diversity management appeared to be widely accepted at RETAIL, employees and team leaders also experienced misunderstandings, tensions, and conflict in practice as a result of diversity management. Team leader Cathrin, from the Warehouse, explained: 
'A significant amount of my work time is about dealing with conflict'. Hidden sensemaking about diversity management concerned problems that emerged from working in a diverse environment and from the dynamics of interpersonal conflict. Although these kinds of sensemaking were shared by all team leaders and employees on the floor, whether foreign-born or native-born, they were never articulated by members of top management nor or in front of them; hence, their hidden constitution.

Diversity management causes tensions. Employees particularly saw the management of differences in culture and ethnicity as causing tensions due to different expectations of the relationship between employees and team leaders. In the Canteen, for example, tensions between two foreign-born male employees and their Danish female team leader sometimes erupted into loud arguments. Employees explained that the patriarchal culture of these two male employees made it difficult for them to accept a female leader. During one such loud argument, Marina whispered, 'It has been going on for weeks now. Some of the men in here... Although they might be well educated, they're like, "I am a man and in my culture no woman is going to tell me what to do"'. Many conflicts were about who could request that a task should be done. Abida explained: 'Some of the foreign male employees get very angry when a female employee says to them, "there is a shortage of meatballs", or "could you please redo the trays". It's very frustrating'. Employees experienced tensions emerging from cultural clashes between more democratic Danish and patriarchal perceptions of authority, but at the same time, they noted that conflict and disagreements were often ignored. Team leader Sofia, from the Canteen, explained: 'A lot of anger emerges from internal frustrations. On a daily basis I have employees coming up to me to talk about their frustrations but at the same time they are afraid to communicate their disagreements to each other'.

Language barriers similarly caused many tensions between people. At RETAIL, both English and Danish are used equally as official languages, resulting in many employees switching back and forth between these two languages. This switching back and forth, employees argued, caused many misunderstandings in daily work coordination because many were not skilled in either language. The foreign-born employees, in particular, experienced many frustrations when trying to understand the native-born Danish employees: 'Sometimes I offend the Danish staff and I don't even notice it and it's only later that I realise what's happened. Then it's like "oh man, I may have insulted this guy, now he won't answer my calls"' (Catly, Warehouse). For many employees, 
differences in language proficiency triggered many tensions in daily work coordination, causing frustration to flourish.

Diversity management reduces performance. While many cultural clashes slowed down the pace of work when team leaders and employees had to sort out misunderstandings and deal with conflict, employees additionally explained how the RETAIL diversity values did not always ensure that the best candidate was hired for a job. To illustrate this, we include an observation from the Canteen:

It is lunchtime at the Canteen, and customers are standing in long lines waiting to be served. The atmosphere is hectic with staff running around. Rico works in the "hot meals' line, serving ordered meals to customers: pulled pork burgers, pasta with meatballs. The heat from the food in the steel containers is intense. Rico is tired and his legs are sore from standing up all day, which is not easy when you are not young anymore, Rico confides. 'What do you want?' Rico asks the customers politely. ' 15 meatballs. One, two, three... You are welcome'. The younger worker Maria is next to him waiting impatiently for him to finish his part before she can serve the fries. The line is growing and now reaches all the way down to the Canteen entrance. Rico is bottleneck and Maria’s obvious impatience makes him nervous. She looks at him with disapproval and says, clearly annoyed, 'If you didn't need to count each meatball it would probably go a lot faster'. Rico struggles to follow Maria's pace.

Younger employees, especially, noted that age differences slowed down the pace of work. They highlighted that his was in stark contrast to the dominant sensemaking of diversity management as an unproblematic means that increases performance. While this dominant sensemaking of diversity management was grounded in the notion that RETAIL always hired 'the best person' for a job, many employees nevertheless viewed value-based politics - not talent—as the decisive factor in who got hired at RETAIL, and this often worked counterproductively toward reaching department goals.

Hidden sensemaking concerned the negative dynamics of diversity management, particularly how diversity management in practice often threw up tensions and conflict. Many employees and team leaders experienced working in a diverse environment with different cultures, ethnicities, ages, and language skills as full of tensions in which differences often triggered conflict. 
Hidden sensemaking of diversity management mobilised the ideological resource of social categorisation, essentially articulating that employees prefer to work in homogenous work groups. Although employees clearly knew it was politically incorrect and against RETAIL's ideological norms to talk about problems that emerged from working in a diverse environment, they nevertheless articulated their hidden sensemaking, albeit never in front of top management. While the hidden sensemaking reflected employees' and team leaders' everyday experiences of diverse organising, they clearly presented a less official and less legitimate version of diversity management at RETAIL. We gained access to these sensemaking processes only in small groups or during oneto-one talks with employees, demonstrating a gap between the official ideological norms of positive dynamics of diversity management articulated by top management and the actual everyday experiences and enactments by employees. In this gap, employees refrained from voicing their disagreement with each other, and the team leaders did the best they could to manage diversity at RETAIL so that it could work to its best ability.

\section{Forbidden sensemaking of diversity management}

The forbidden sensemaking of diversity management was also a hidden type of sensemaking, but it was strongly characterised by secrecy and taboo. Unlike the hidden sensemaking, which was relatively freely articulated by employees and team leaders, the forbidden sensemaking of diversity management was expressed only by the foreign-born minority employees. Our first encounter with this sensemaking highlights the pervasive anxiety associated with this way of thinking about diversity management:

During an interview with Yegor at the Warehouse, we routinely ask about differences at work. Yegor glances around nervously to see if we are being watched and then quietly suggests that we find somewhere quieter to talk. After walking down long aisles of tall shelves with products, we arrive at a very secluded area at the back of the Warehouse. Completely surrounded by cardboard boxes on wooden pallets, Yegor now feels safe to talk about what it is like to work at RETAIL.

This observation illustrates how speaking negatively about diversity management at RETAIL could take place only covertly in informal settings so that nobody would hear the conversation. In this 
prohibited, covertly expressed account, the foreign-born minority employees associated diversity management with feeling discriminated against and exploited by RETAIL.

Foreign-born employees are constrained to the lowest place in the hierarchy. Not all departments at RETAIL were equally diverse. Sales and top management, for example, were staffed only with native-born Danes and other Scandinavians all in their 30s and 40s, whereas departments such as the Canteen and the Warehouse were diversely staffed with many foreign-born employees. At the Warehouse, Yegor evoked hierarchy to explain this structural relationship:

'Everyone definitely wants to work at the office and that's why Sales has got the highest prestige among all the departments. The work there isn't physically hard at all. The physically hardest jobs are lowest in prestige and that's why no Danes work at our department'.

The foreign-born employees worked primarily in the labour-intensive departments, which were lowest in the organisational hierarchy. Many of them felt isolated from the rest of the organisation, with no contact with customers or native-born Danish employees. Kadri, another foreign-born Warehouse worker, explained: 'We really try to reach out to the Danish co-workers, but it's as if they are afraid of us. They give us nicknames, call us "the Polish workers" even though none of us are from Poland'. Many of the foreign-born employees felt that that their employment at RETAIL was really about securing enough employees who were willing to do the hard and dirty work that the native-born Danish employees would not do. They talked about diversity management as a cover for securing a hardworking workforce, which was also cheap. While stirring in a large pot of stew, Kate, a Philippine worker at the Canteen, quietly whispered her prohibited interpretation of why diversity management had become so pervasive at RETAIL:

'It's because we are cheap labour. That's what it feels like. I have worked here 19 years and I never got a raise or compensation. ... But, it happens often [sighs deeply], there's this Danish boy who's only been here a couple of months and already he gets more than me'. 
Like Kate, many foreign-born employees had disappointedly discovered that their employment at RETAIL was a way to keep salary costs low because they would settle for less pay than the native-born Danish employees. Their inadequate language skills and lack of network made it difficult to change jobs, which turned them into a very stable workforce. To them, diversity management was certainly about doing good for business but at the cost of people. However, the particular circumstances under which such sensemaking about diversity management was communicated, covertly, in informal settings or by the use of nervous whispers denoting fear and anxiety, indicates the forbidden and illegitimate nature of these interpretations of diversity management.

Many of the foreign-born employees talked about how they had been promised future career opportunities when they first joined RETAIL, which then were nonexistent. It was virtually impossible for them to climb the corporate ladder or even shift between departments despite RETAIL's official rhetoric that anyone can become something. Arvi from the Warehouse explained:

'When I first came to RETAIL, I worked fifty-five hours a week for two years. I was promised a promotion and more responsibility, but nothing ever happened even though I did everything they asked me to. So, I got very angry. I even applied for another position here, but they told me that I wasn't ready because I don't speak Danish'.

Arvi's experience of inconsistencies between his expectations of promotion and the reality of not being promoted threatened his identity, fuelling his sensemaking with anger as he tried to explain why the promotion did not happen. He felt he had been strung along. Right from the start, he had felt excluded from the Danish network at RETAIL, and now he was told that his inadequate Danish language skills was the reason that he they could not advance to another job. However, fearing that his anger would defy cultural conventions at RETAIL and get him fired, he supressed his grievances and controlled his emotions so that they became appropriated to RETAIL diversity values. Team leader Cathrin confirmed that fear was the primary reason that none of the foreign-born employees protested against perceived injustices:

'Peter, who is the manager of our department, well ... the employees are scared of telling him if something is wrong, and they only tell him the good stuff. So this is the only 
information that reaches the management group. I am a middle level team leader, and if I try to push forward with an issue, top management doesn't really listen to me. However, the problem is that the employees are too scared to say anything. So nothing moves upwards. Even though we all say that we are a flat organisation, there is still a very strict hierarchy here'.

Driven by fear of experiencing negative consequences such as unwanted job loss, the foreign-born employees supressed their negative experiences of discrimination and exploitation and kept their grievances to themselves. To reduce fear, they engaged in habituated silence (Kish-Gephart et al., 2009), a form of resignation that minimised exposure to threatening situations that might trigger disappointment and anger. Thus, to remain in control, the foreign-born employees engaged in a type of emotional labour in which they control how they feel about working at RETAIL; in particular, they tried to enact emotional displays consistent with the value that diversity management always does good. These are implicit feeling rules not found in training manuals or job descriptions but constructed in social interactions in which negative sentiments about diversity management are devalued and positive ideologies of diversity management are celebrated. Although the latter constitute specific power relations framing the politics of social interaction, it is not acknowledged formally but experienced informally by the foreign-born employees doing the hard labouring jobs. The elimination of voice on their part reduces the upward information flow so that only the successes of RETAIL's diversity values are celebrated.

Moreover, the emotional bond between foreign-born employees' and RETAIL leads them to suppress their accounts of discrimination and exploitation. Basically, these employees felt that they had good and stable jobs because of RETAIL's dominant ideologies of diversity management, and many had hopes that one day, they would advance to another department. Thus, their subjection to the relation of belief on one hand legitimised the potential positive dynamics of diversity management, while, on the other, first-hand experiences of discrimination and exploitation left them feeling very ambiguous about working at RETAIL. A way of dealing with this ambiguity was to control their emotions and thoughts so as to be in accordance with those ideologies and feeling rules legitimated at RETAIL; thus, only a certain terrain of possible action would unfold. Resisting submissiveness and enacting disobedience would break their emotional commitments to RETAIL; thus, this emotionality 
represented an emotional barrier to voicing protests and taking action. The foreign-born employees therefore endured discrimination and exploitation and continued to articulate forbidden sensemaking only in secrecy.

\section{Discussion}

In this paper, we combined a sensemaking (Weick, 1979; 1995; Weick et al., 2005) lens with Mumby and Putnam's (1992) conception of power in poststructuralist feminism, to concentrate on a variety of sensemaking resources that shape the terrain within which organisational actors at RETAIL interpret, enact, and emotionally experience diversity management at work. One of the advantages of applying the sensemaking perspective to organisational phenomena is its ability to capture the lived experiences of social organising, adding richness to our understanding of the complex content of human conditions.

We have addressed two research questions in this article. The first asked what ideological resources the diverse workforce at RETAIL mobilises in its sensemaking and enactment of diversity management practices. Our findings show that organisational actors with different sociodemographic backgrounds, including foreign-born minorities, and in various organisational positions, including less privileged ones, evoke multiple ideologies when they talk about diversity management and what it is like to work in a diverse work environment. Inspired by Wetherell et al. (1987), who argue that it is by examining the contradictions of people's interpretations that we get to understand the operations of ideology, we found that organisational actors at RETAIL interpreted diversity management through a hierarchical system of dominant, hidden, and forbidden sensemaking. This hierarchical system of sensemaking mobilised competing and oftentimes contradictory ideologies of diversity management rooted in the business case, social justice, social categorisation, and exploitation.

Top management articulated only positive ideologies of diversity management to strategically shape employee sensemaking toward noticing, interpreting, and collectively enacting only the positive dynamics of diversity management. We, however, found that employees' hidden and forbidden sensemaking revealed meaning struggles over which and whose experiences of diversity management should gain privilege. These contradictions arose from the ways that employees at RETAIL talked about diversity management in formal versus informal settings. Their accounts about the negative dynamics of diversity management in terms of conflict and exploitation were expressed only in informal settings, as they could not openly coexist with the dominant 
sensemaking of diversity management as being good for business and people. Thus, the more negative ideologies were obscured and hidden from management. In effect, the dominant accounts solely portrayed diversity management at RETAIL as something that worked to benefit everybody in the organisation. We therefore suggest that an important aspect of understanding the influence of heavily legitimated institutionalised values on sensemaking, such as ideologies of diversity management, is to consider the variety of sensemaking resources shaping what groups notice and how they act, of which formal authority and formally legitimated values represent only one side. Future sensemaking analyses need to describe in more detail the complex content and contradictions of people's sensemaking, because it is through insights into these that we gain better understanding of the operations of values as legitimating ideology, how it is maintained and reproduced, and how it may be corroded in and by the employees. While the rhetoric of policies on one hand empower employees, their experiences in practice may frame the rhetoric as something to be endured while causing deep-seated emotional angst with little or no opportunity for legitimate expression.

The second research question asked what characterises the political processes of sensemaking about diversity management practices through which organising occurs. We show that a strong identification with an organisation's values subjects employees to a relation of belief in the legitimacy of the positive dynamics of these values. As argued by Mumby and Putnam (1992), control of emotions always occurs when cultures are managed through the inculcation of specific values. The relation of belief is sustained through the mobilisation of positive emotions, which signify that it is fun and enjoyable to work in a diverse environment and it becomes the means for individuals at RETAIL to adapt to the diverse organisational culture. These positive emotions reciprocally reinforce a social bond between the RETAIL top management and the employees and team leaders, ensuring that they sustain their commitments to the social structures at RETAIL. The foreign-born employees were also subjected to these beliefs, despite experiencing exploitation and discrimination at work. These beliefs were powerful in that they controlled their emotions and thinking to agree with ideologies and feeling rules that legitimised potential valorisation of diversity management. The strong identification with the organisation's values was the means of manufacturing consent from all employees and team leaders, no matter how they experienced diversity management in practice. Thus, identification served to mobilise power to maintain and reproduce the economic and political interests of RETAIL. These processes of organisational politics are the stuff of everyday practices of diversity management at RETAIL. 
While the dominant sensemaking of diversity management was heavily influenced by top management's persuasive sensegiving about its positive effects, the political processes of sensemaking not only included personalised direct exercises of power but also presented power as a systemic force, working so that highly institutionalised and legitimated meanings had become fixed in specific ways. This is important because once particular meanings become fixed, they exercise a profound influence on local tacit and explicit rules of appropriate attitude and behaviour among employees and management, shaping the collectively enacted environment.

\section{Theoretical contributions}

Our findings about the political processes of sensemaking have theoretical implications for sensemaking research. While the political processes of sensemaking were initially overlooked in sensemaking studies, there is now a growing body of literature acknowledging the contested nature of meaning in processes of organising. Following several calls for sensemaking studies to advance our understanding of sensemaking and power in organisations (Maitlis \& Christianson, 2014, Mills et al., (2010), Sandberg \& Tsoukas, 2015), we have tried to attend more closely to the political processes through which some sensemaking gains legitimacy while others remain marginalised. The current paper adds to this literature by developing the sensemaking perspective to also consider the complex mechanisms that are employed to control the definition of a specific situation, implicating subjects in a particular social ordering of collective organising. We have specifically shown that in diversity management, the political processes of sensemaking deeply implicate emotions as a central force that facilitates the ongoing reproduction of social order. Political processes play a central role in the manufacture of consent through which certain sensemaking is maintained as dominant while others are forbidden. At RETAIL, all foreign-born employees appeared nervous or anxious when expressing their critical thinking about diversity management, indicating that they were extremely aware of the forbidden and illegitimate nature of their interpretations. Engaging in emotion management to control their feelings of anger and fear, they knew that such authentic emotional expressions would defy cultural conventions at RETAIL.

As argued by Mumby and Putnam (1992), emotion management always occurs because of a need to remain in control. Stavrakakis (2008) uses Milgram's famous social-psychological experiment from the early 1960s to argue that crucial emotional barriers occur in passing from compliance to dissent and from dissent to disobedience. While employees at RETAIL were positioned somewhere between compliance and dissent, this position triggered feelings of 
ambiguity toward their employment at RETAIL. Their way of dealing with this ambiguity was to control their emotions and thinking so that they would be in accordance with dominant ideologies and feeling rules, unfolding a terrain of action that emphasised submissiveness and emotional commitment to RETAIL. While RETAIL, as part of its organising, capitalises on this kind of employee loyalty, employees nevertheless risk estranging themselves from their work as they become more aware of their emotional dissonance. Thus, we see sensemaking, power, and emotions as a complex nexus, which holds considerable developmental scope for future work.

Our contribution to the critical diversity literature shows that the sensemaking perspective can contribute to understanding of how diversity management is experienced and practiced very differently in different locations. Similar to Schwabenland and Tomlinson (2015), we have directed attention to the shadow side of diversity management by showing that the organisation's espousal of diversity management frames noncompliance with its contours as necessarily alien to these values. Indeed, being against diversity practices could be taken as a sign of a lack of emotional control on the part of those unable to accede to the project of being a politically correct member of Danish society. While compliance on the part of the native-born Danish employees makes them feel good about themselves, compliance on the part of many of the foreign-born employees only makes them feel, as it were, alienated. The values of diversity management stipulate a frame for political correctness subordinating possibilities for dissent as they fuel the fires of its hidden resentment and emotionality. Enduring acquiescence to this framing ensures a job; expressing dissent in public is to display one's self as unworthy of a job in the space created by these values, because one is insufficiently civil and emotionally mature to live in accord with these values. These terms of exchange thus simultaneously legitimate that which they stigmatise, ensuring that the very structural conditions they rhetorically oppose are practically reproduced.

\section{Implications for practice}

Our arguments also have implications for practice. While RETAIL is renowned for its central values of and mission to diversity and inclusion, there is nevertheless a gap between official management statements about how diversity management adds value to the organisation and actual experiences of diversity management by especially foreign-born employees. This gap appears because only a very narrow and positive interpretation of diversity management is allowed articulation, while more negative interpretations remain taboo. The analysis shows mechanisms that especially prevent the foreign-born employees from voicing their concerns with discrimination and 
exploitation, essentially inhibiting change in the practices of diversity management at RETAIL. A significant step forward would, however, be to challenge the romantic official story of diversity management at RETAIL by articulating the experiences of different employee groups. We therefore suggest that managers and diversity practitioners should become aware of and address both the positive dynamics and the problems that employees experience when working in a diverse environment. If language competence is the sign that masks commitment to better practice of diversity management, then the organisation should commit to improving competences and capabilities in this sphere rather than indiscriminately allowing this ability to be uncultivated. This way, management might not only talk the talk of diversity management but actually practice it in ways that deliver a difference all too missing in its present commitments.

\section{Conclusion}

An important but understudied issue in the study of organisational sensemaking concerns how power and politics influence sensemaking processes, specifically the political struggles immanent in collective processes of meaning construction and organising. Exploring the ideological resources that a diverse workforce mobilises in their sensemaking and enactment of diversity management, this study combined the sensemaking perspective with Mumby and Putnam's (1992) poststructuralist feminist conception of power to attend more closely to the political processes of sensemaking. Zooming in on the mechanisms through which some sensemaking becomes legitimate while others remain marginalised, we concentrated on a variety of sensemaking resources that shape the terrain within which organisational actors at RETAIL interpret, enact, and emotionally experience diversity management at work. We provide insight into the complex mechanisms that are employed to control the definition of a specific situation, implicating subjects in a particular social ordering of collective organising, and we conclude that the political processes of sensemaking deeply implicate emotions as a central force that facilitates the ongoing reproduction of social order. Our study therefore highlights the need to conceive of sensemaking, power, and emotions as a complex nexus of the micro-political practices in which certain terrains of action unfold, allowing collective organising to occur.

\section{References}

Alvesson, M., \& Karreman, D. (2000). Varieties of discourse: On the study of organizations through discourse analysis. Human relations, 53(9), 1125-1149. 
Balogun, J., \& Johnson, G. (2004). Organizational restructuring and middle manager sensemaking. Academy of management journal, 47(4), 523-549.

Boxenbaum, E. (2006). Lost in Translation: The Making of Danish Diversity Management, American Behavioural Scientist 49: 939-948.

Brown, A. D. (2005). Making sense of the collapse of Barings Bank, Human Relations 58(12), $1579-1604$.

Brown, A. D., Stacey, P., \& Nandhakumar, J. (2008). Making sense of sensemaking narratives. Human relations, 61(8), 1035-1062.

Braun, V., \& Clarke, V. (2006). Using thematic analysis in psychology, Qualitative Research in Psychology 3 (May 2015), 77-101.

Calás, M. B., \& Smircich, L. (1999). From ‘the woman's' point of view: Feminist approaches to organization studies, in S. Clegg and C. Hardy (eds) Studying organization: Theory and method, 212-251.

Christensen, J. F., \& Muhr, S. L. (2018). Desired diversity and symptomatic anxiety: theorising failed diversity as Lacanian lack. Culture and Organization, 24(2), 114-133.

Cox, T.H., \& Blake, S. (1991). Managing cultural diversity: Implications for organizational competitiveness. Academy of Management Executive 5(3), 45-56.

Daft, R., \& Weick, K. (1984). Toward a model of organizations as interpretation systems, Academy of Management Review 9(2), 284-295.

Foucault, M. (1980). Power/knowledge: Selected interviews and other writings, 1972-1977. Pantheon.

Garfinkel, H. (1967). Studies in Ethnomethodology. Evanston: Northwestern University Press.

Gephart, R. P. (1993). The textual approach: Risk and blame in disaster sensemaking. Academy of management journal, 36(6), 1465-1514.

Ghorashi, H., \& Sabelis, I. (2013). Juggling difference and sameness: Rethinking strategies for diversity in organizations. Scandinavian Journal of Management 29(1), 78-86.

Gioia, D., \& Chittipeddi. K. (1991). Sensemaking and sensegiving in strategic change initiation', Strategic management journal 12(6), 433-448.

Gioia, D. A., Thomas, J. B., Clark, S. M., \& Chittipeddi, K. (1994). Symbolism and strategic change in academia: The dynamics of sensemaking and influence. Organization science, 5(3), 363-383.

Gubrium, J., \& Holstein, J. (2009). Analyzing Narrative Reality, Thousand Oaks, CA: Sage. 
Hansen, H. (2006). The Ethnonarrative Approach. Human Relations 59: 1049-1075

Hardy, C. (2001). Researching organizational discourse, International Studies of Management and Organization 31(3), 25-47.

Heaney, J. G. (2011). Emotions and power: reconciling conceptual twins. Journal of Political Power, 4(2), 259-277.

Hochschild, A. R. (1990). Ideology and emotion management: A perspective and path for future research. Research agendas in the sociology of emotions, 117, 117-142.

Holck, L. (2015). Embedded Diversity: A critical ethnographic study of the structural tensions of organizing diversity. Frederiksberg, Denmark: CBS.

Holck, L., \& Muhr, S.L. (2017). Unequal solidarity? Towards a norm-critical approach to welfare logics, Scandinavian Journal of Management 33: 1-11

Holvino, E., \& Kamp, A. (2009). Diversity management: Are we moving in the right direction? Reflections from both sides of the North Atlantic, Scandinavian Journal of Management 25(4), 395-403

Janssens, M., \& Zanoni, P. (2014). Alternative diversity management: Organizational practices fostering ethnic equality at work. Scandinavian Journal of Management 30(3), 317-331.

Kish-Gephart, J. J., Detert, J. R., Treviño, L. K., \& Edmondson, A. C. (2009). Silenced by fear: The nature, sources, and consequences of fear at work. Research in Organizational Behaviour, 29, 163-193.

Lukes, S. (1974) Power: A Radical View. London: Macmillan.

Maitlis, S. (2005). The social processes of organizational sensemaking, Academy of Management Journal 48(1), 21-49.

Maitlis, M., \& Christianson, M. (2014). Sensemaking in Organizations: Taking Stock and Moving Forward. The Academy of Management Annals 8: 57-125.

Maitlis,S., \& Sonenshein, S. (2010). Sensemaking in crisis and change: Inspiration and insights from Weick (1988), Journal of Management Studies 47(3), 551-580.

Mills, J. H., Thurlow, A., \& Mills, A. J. (2010). Making sense of sensemaking: the critical sensemaking approach, Qualitative Research in Organizations and Management: An International Journal 5: 182-195.

Mikkelsen, E. N. (2013). An analysis of the social meanings of conflict in nonprofit organizations. Nonprofit and Voluntary Sector Quarterly, 42(5), 923-941. 
Mumby, D. (1987). The political function of narrative in organizations, Communications Monographs 54(2), 113-127.

Mumby, D. K., \& Putnam, L. L. (1992). The politics of emotion: A feminist reading of bounded rationality. Academy of management review, 17(3), 465-486.

Özbilgin, M., Tati, A., Ipek, G., \& Sameer, M. (2014). The Business Case for Diversity. London: ACCA.

Patriotta, G. (2003). Sensemaking on the shop floor: Narratives of knowledge in organizations', Journal of Management Studies 40(2), 349-375.

Putnam, L. L., \& Mumby, D. K. (1993). Organizations, emotion and the myth of rationality. Emotion in organizations, 1, 36-57.

Risberg, A., \& Søderberg, A. M. (2008). Translating a management concept: Diversity management in Denmark, Gender in Management: An International Journal 23 (6), 426-441.

Sandberg, J., \& Tsoukas, H. (2015). Making sense of the sensemaking perspective: Its constituents, limitations, and opportunities for further development. Journal of Organizational Behaviour, $36(\mathrm{~S} 1)$.

Schwabenland, C., \& Tomlinson, F. (2015). Shadows and light: Diversity management as phantasmagoria. human relations, 68(12), 1913-1936.

Statistics Denmark (2017). Indvandrere i Danmark. Befolkning og valg. København, Statistics Denmark.

Stavrakakis, Y. (2008). Peripheral vision: subjectivity and the organised other: between symbolic authority and fantasmatic enjoyment. Organization Studies, 29(7), 1037-1059.

Tatli, A. (2011). A multi-layered exploration of the diversity management field: Diversity discourses, practices and practitioners in the UK. British Journal of Management 22(2), 238253.

Tatli, A. and Özbilgin, M. (2012). An Emic Approach to Intersectional Study of Diversity at Work: A Bourdieuan Framing, International Journal of Management Reviews 14 (2), 180-200.

Tracy, S. (2013). Qualitative Research Methods: Collecting evidence, crafting analysis, communicating impact, Chichester: Wiley-Blackwell.

Weick, K. E. (1993a). Sensemaking in organizations: Small structures with large consequences. Social psychology in organizations: Advances in theory and research, 10-37.

Weick, K. E. (1979). The Social Psychology of Organizing (2nd ed.). Reading, Massachusets: Addison-Wesley Pub. Co. 
Weick, K. (1993b). The collapse of sensemaking in organizations: The Mann Gulch disaster, Administrative Science Quarterly 38, 628-652.

Weick, K. (1995). Sensemaking in organizations. London: Sage.

Weick, K., Sutcliffe, K. and Obstfeld, D. (2005). Organizing and the Process of Sensemaking, Organization Science 16(4), 409-421.

Wetherell, M., Stiven, H., \& Potter, J. (1987). Unequal egalitarianism: A preliminary study of discourses concerning gender and employment opportunities. British Journal of Social Psychology, 26(1), 59-71.

Wrench, J. (2005). Diversity management can be bad for you. Race and Class 46(3), 73-84.

Zanoni, P., Janssens, M., Benschop, Y., \& Nkomo, S. (2010). Unpacking Diversity, Grasping Inequality: Rethinking Difference Through Critical Perspectives, Organization 17(1), 9-29. 